\title{
Daily Stress and Affect Across Adulthood: The Role of Social Interactions via Different Communication Modes
}

\author{
Xin Yao Lin and Margie E. Lachman \\ Department of Psychology, Brandeis University
}

\begin{abstract}
Communication with one's social network can take place in person or using technology. Past studies have mainly focused on the effects of communication modality (in-person, telephone calling, text messaging, and internet) on stress and affect at a betweenperson level by exploring the individual differences. Yet few studies have compared such effects at a within-person level, that is, how an individual varies over time. We conducted a diary study over 7 days for 145 participants (ages 22-94) mostly from the greater Boston area to test the role each communication mode played in daily stress exposure, stress reactivity, and positive and negative affect using within-person analyses. Multilevel modeling results revealed that days with more frequent text messaging were associated with greater stress exposure and negative affect. Days with more in-person communication were associated with more positive affect. Days with more telephone calls were associated with less negative affect. Internet communication was not associated with stress or affect at a within-person level. To address the directionality of our findings, we also conducted lagged analyses that suggested that higher previous-day frequency of text messaging was related to higher stress exposure on the subsequent day. In addition, higher previous stress exposure was related to less telephone calling on the subsequent day. Implications and future research are discussed with a focus on how social interactions via different communication modes with one's social network can make a difference for daily well-being.
\end{abstract}

Keywords: social interactions, computer-mediated communication, in-person communication, daily stress, positive and negative affect

With the proliferation of numerous electronic devices, computermediated communication (CMC) today allows for a wide range of social interactions with friends and family members via different communication modes-text messaging, social media, and online chats. CMC makes social interactions possible for individuals at any location, time, and setting. Therefore, it is important to recognize that social interactions between individuals can occur across multiple platforms. Past research has primarily focused on CMC for young adolescents and young adults (Vanden Abeele et al., 2017). However, recent decades saw a drastic increase in CMC in midlife and older adults (Pew Research Center, 2017d). Thus, it is essential to include adults of all ages when examining different usages of communication modes.

Social relationships are associated with daily stress. Daily stressors are challenges individuals experience on a daily basis, which may consist of everyday concerns and unexpected events that interfere with their day-to-day life (Almeida, 2005). Many of the stressors identified were associated with interpersonal relationships. Between-person analyses have shown that more CMC such as text messaging and the internet were associated with more stress (Thomée et al., 2011). However, the role that communication modes play in daily stress at a within-person level is not known.

Past research has also illustrated the importance of communication modes for positive and negative affect. Positive affect refers to the extent to which an individual feels energetic, concentrated, and full of enjoyable engagement. Negative affect is characterized by a person's perceived distress and unenjoyable engagement, which consists of various adverse moods (Watson et al., 1992). Betweenperson analyses have shown that more social interaction, particularly in-person interaction, is associated with more positive affect
Action Editor: Danielle S. McNamara was the action editor for this article. ORCID iD: Xin Yao Lin (ID https://orcid.org/0000-0002-1244-5387

Conflict of interest: none.

Disclosure and Acknowledgment: This research was supported by a grant from the National Institute on Aging \#RO1 AG 17920 and this funding source had no other involvement other than financial support. In addition, we would like to thank Alycia Sullivan Bisson, Jenna DeFrancisco, Mona Zheng, Brandeis University writing center, and Lifespan Developmental Psychology Lab members.

If interested in using the data or seeing the instruments used for the current study, please contact the authors.

The current study examined different variables compared with prior publications that used this dataset. Specifically, prior publications focused on control beliefs, cognition, physical activity, happiness, and selection, optimization and compensation (SOC), which differed significantly from the aims of the current study. Prior uses of data include the following published articles: Rickenbach et al. (2019), Robinson et al. (2016), Robinson and Lachman (2018) and Teshale and Lachman (2016).

Open Access License: This work is licensed under a Creative Commons Attribution-NonCommercial-NoDerivatives 4.0 International License (CC-BYNC-ND). This license permits copying and redistributing the work in any medium or format for noncommercial use provided the original authors and source are credited and a link to the license is included in attribution. No derivative works are permitted under this license.

Disclaimer: Interactive content is included in the online version of this article.

Contact Information: Correspondence concerning this article should be addressed to Xin Yao Lin, Department of Psychology, Brandeis University, Waltham, MA 02452, United States. Email: xylin@ brandeis.edu 
compared with text or instant messages (Holtzman et al., 2017; Sacco \& Ismail, 2014). The relationship between communication modes and negative affect is mixed, with some studies showing little or no effect for any communication modes and some studies showing that more CMC usage is associated with more negative affect (Holtzman et al., 2017; LaRose et al., 2014). However, little is known regarding the role that communication modes play in positive and negative affect at a within-person level. To what extent are variations in daily affect related to differences in communication modes used (in-person, telephone calling, text messaging, and internet)?

\section{Literature Review}

\section{Social Interactions via Different Communication Modes}

There has been a sharp rise in recent years of social connections via text messaging and the internet for social media platforms. Smartphones, internet usages, and social media platforms were no longer only occupied by young adults. As of $2010,72 \%$ of adults use text messages (Pew Research Center, 2010). The numbers continue to rise and as of $2016,88 \%$ of those aged $30-49,74 \%$ of $50-64$ years old, and $42 \%$ of 65 years and older own a smartphone (Pew Research Center, 2017b). Approximately $96 \%$ of those aged $30-49,87 \%$ of $50-64$ years old, and $64 \%$ of people 65 years and older use the internet to connect with others and gather information regularly (Pew Research Center, 2017a). Additionally, approximately 70\% of Americans use social media to communicate with others, and engage and share information, which represents a dramatic increase since 2005 when only $5 \%$ of Americans used one of the social media platforms. By 2016, 64\% of the population, 50-64 years old, and $34 \%$ of the population over 65 years old use at least one social media site (Pew Research Center, 2017c). These dramatic increases in CMC among adults of all ages bring the question of the role multimodal communication plays in the context of one's daily life.

\section{Theoretical Perspectives}

\section{"Cues Filtered out" Theory}

"Cues filtered out" (CFO) theory explains how CMC and inperson interactions differ and influence social relationships. This theory states that text-based CMC lacks verbal and nonverbal physical and social cues in social interactions. Individuals using CMC experience reduced social context cues because they cannot observe gestures, voice tones, and facial expressions of others. In contrast, in-person interactions provide rich verbal and nonverbal cues that enhance social relationships (Sproull et al., 1991).

The CFO theory has also been linked to affect and stress. Nonverbal cues such as smiles and laughs are easily contagious and prone to mimicry during in-person or telephone communications (Hess \& Fischer, 2013), which can increase one's positive mood and reduce one's negative mood (Tsujita \& Rekimoto, 2011). The social and physical presence of others can also provide more support for individuals under stress (Holtzman et al, 2017; Jakubiak $\&$ Feeney, 2016). Contrary to in-person and telephone communications, nonverbal, verbal, social and physical cues are much less prominent in text-based CMC: People are more likely to overestimate their accuracy in conveying their emotions (e.g., sarcasm and humor) through text-based CMC than in-person and voice communication (Kruger et al., 2005). The misinterpreted emotions can lead to adverse reactions. In other words, if one is in conflict with others, $\mathrm{CMC}$ can escalate the conflict because of the misinterpretation of others' emotions (Derks et al., 2008), which can lead to more interpersonal stress (Holtzman et al., 2017).

\section{Empirical Studies}

\section{Stress}

Stress exposure and reactivity are related to interpersonal occurrences. A description of stressor content measures from the National Study of Daily Experiences (NSDE) data showed that $50 \%$ of stressful events occurred due to an argument or tension with others, and the second highest occurrence of stressful events (15.4\%) occurred because of an event that happened to others within the participant's network. In addition, perceived reactivity to stressful events that happened to one's family and friends was rated the highest among all stressor contents (Almeida et al., 2011).

Given the relationship between interpersonal relations and stress, it is important to examine how social interaction via different communication modes affects stress. Some research has shown that CMC increased one's stress (Thomée et al., 2011). A one-year follow-up study for young adults showed that high mobile phone usage at baseline increased risks for poor health symptoms at the follow-up (Thomée et al, 2011). More internet communication such as email and social media platforms was also associated with more stress. One study revealed that the more time people spent on emails, the more they felt a sense of overload and stress (Barley et al., 2011). Online social networks were also shown as a source and symbol of stress (Maier et al., 2012) caused by social interaction overload (Laumer et al., 2013) in which the social network users felt they provided too much social support to other users. On social network sites such as Facebook, users feel the need to react to the constant stream of new messages and posts each time they $\log$ on. This form of social interaction might lead to social overload (Maier et al, 2012). Social network users also experienced social network fatigue. This fatigue resulted from staying socially connected for too long due to the copious amount of content available on social networks, which led to stress (Ravindran et al., 2014). A study in Germany examined German internet users between the ages of 14 and 85 years old and revealed that more private emails and social media messages resulted in a communication load that was positively related to perceived stress (Reinecke et al., 2017). In addition, in-person support was more effective than text messages in times of stress (Holtzman et al., 2017). Thus, growing evidence suggests that social interaction via different communication modes makes a difference for stress.

\section{Positive and Negative Affect}

The quantity of social interactions and positive affect are strongly related. Watson (1988) examined the relationship between social interactions in terms of the number of hours participants spent with friends during the day and one's daily positive and negative affect. Results suggested that social interactions were positively correlated with positive affect, such that more time spent interacting with friends was related to more positive affect at a within-subjects level. To explore the causal effect, an experimental study revealed that 
one's positive affect increased after a social interaction with a classmate who was previously unknown to the participant (McIntyre et al., 1991). Recent studies found that in-person communication was also related to more positive affect compared with other communication modes. Compared with CMC, people's emotions tend to be more positive and less negative after in-person communication (Kafetsios et al., 2017). Receiving support in-person was also related to higher positive affect and social belongingness compared with texting or instant messages (Holtzman et al., 2017; Sacco \& Ismail, 2014).

In contrast to positive affect, the correlation between social activities and negative affect has been inconsistent and mixed. Some studies revealed no relationships between negative affect and type and amount of social interactions, whereas other studies presented a weak relationship (Watson et al., 1992). In addition, negative affect was not changed after instances of social interaction (McIntyre et al., 1991). The roles that communication modes play on negative affect were also mixed. Some recent studies noted that in-person or text messaging was not related to negative affect (Holtzman et al., 2017). Other studies reported that CMC such as telephone calling and instant messaging reduced negative affect (Sacco \& Ismail, 2014). CMC has also distracted and reduced enjoyment for individuals during in-person interactions (Przybylski \& Weinstein, 2013), which predicted worse moods (Dwyer et al., 2018).

\section{Current Study and Hypotheses}

Few studies have examined the frequency of contact with friends and family members in one's social network across adulthood while specifying the communication mode the participants used. Thus, the current study examined the daily frequency of each communication mode usage (in-person, telephone calling, text messaging, and internet). In addition, most research on stress and affect in relation to social interactions via different communication modes has focused on adolescents and young adults in college. Little is known regarding the relationship between communication modes, daily stress, and affect for adults beyond the age of college students. Furthermore, past research has examined each communication mode separately. It is likely that one might speak with a friend in-person and via social media on the same day. The current study took into account the usage of multimodal communication in participants' daily lives by including the frequency of each communication mode in the same model when predicting stress and affect.

Past studies have typically examined social interaction via different communication modes and well-being by comparing across persons and using cross-sectional (one-time survey) or long-term longitudinal (e.g., once every year) design but have not considered daily variations within persons. However, individuals' usage of different communication modes and their well-being can differ on a day-to-day basis (Almeida, 2005; Antonucci et al., 2017; Cornwell, 2011). The present study used within-person analyses to examine whether days with more social interaction via different communication modes would be associated with more or less stress and affect for the same individual across 1 week.

\section{Hypotheses}

Based on the past studies and the CFO theory, it was predicted that at a within-person level, days with more in-person communication and telephone calling would be associated with less stress exposure (1 A \& 1B), reactivity ( 2 A \& 2B), negative affect (4 A \& 4B), and more positive affect ( $3 \mathrm{~A} \& 3 \mathrm{~B}$ ). Moreover, days with higher usage of text messaging and internet would be associated with more stress exposure (1C \& 1D), reactivity (2C \& 2D), negative affect (4C \& 4D), and less positive affect (3C \&3D) (Figure 1).

\section{Exploratory}

In order to examine the directionality of the relationships, lagged relationships between each communication mode and the outcome variables (stress and affect) were tested to explore whether the frequency of each communication mode on the previous day was related to stress and affect on the subsequent day and vice versa.

\section{Figure 1}

The "CFO" Theory and Hypotheses

\begin{tabular}{|c|c|c|c|c|c|}
\hline & & \multicolumn{4}{|c|}{ Hypotheses } \\
\hline \multicolumn{2}{|c|}{ "Cues Filtered Out" (CFO) Theory } & $\begin{array}{l}\text { 1. Stress } \\
\text { Exposure }\end{array}$ & $\begin{array}{l}\text { 2. Stress } \\
\text { Reactivity }\end{array}$ & $\begin{array}{l}\text { 3. Positive } \\
\text { Affect }\end{array}$ & $\begin{array}{l}\text { 4. Negative } \\
\text { Affect }\end{array}$ \\
\hline \multirow{2}{*}{$\begin{array}{c}\text { More Nonverbal, Verbal, } \\
\text { Social or Physical Cues }\end{array}$} & A. In-Person & & & 亿 & $\checkmark$ \\
\hline & B. Telephone & & & 口 & ת \\
\hline Less Nonverbal, Verbal, & C. Text Messaging & te & $\square$ & 7 & 仓 \\
\hline Social or Physical Cues & D. Internet & & $\boldsymbol{1}$ & $\mathrm{n}$ & $\boldsymbol{1}$ \\
\hline
\end{tabular}

Note. According to the "CFO" theory, in-person and telephone interactions provide more verbal, nonverbal physical, or social cues, which can increase positive affect and decrease stress and negative affect. In contrast, text-based communication (text messaging and the internet) has less verbal, nonverbal, physical, or social cues in social interactions, which can decrease positive affect and increase stress and negative affect. Thus, it was predicted that at a within-person level, days with more in-person communication and telephone calling would be associated with less stress exposure (1 A \& 1B), reactivity ( 2 A \& 2B), and negative affect (4 A \& 4B), and more positive affect (3 A \& 3B). Moreover, days with higher usage of text messaging and internet would be associated with more stress exposure (1C \& 1D), reactivity (2C \& 2D), negative affect (4C \& 4D), and less positive affect (3C \&3D). The supported hypotheses are represented with green arrows and those that were predicted but not supported are shown with black arrows. 


\section{Method}

\section{Participants}

Participants $(N=145)$ ranging from 22 to 94 years old were recruited from mostly the greater Boston area with local newspapers, local signs, and online advertisements for the Daily Experiences and Memory study, which was conducted for a period of 7 days. The participants were stratified by age, sex, and educational attainment. This study consisted of $40 \%$ males and $60 \%$ females with a mean age of 51 (SD = 19). Education level for the participants ranged from high school to doctoral level, and most received at least some level of college education with an average of 15 years of education $(S D=2)$. Participants in the study consisted of $73.1 \%$ White, $15.2 \%$ Black or African American, 4.9\% Hispanic or Latin American, 2.1\% Asian, and the rest were more than one race. Participants were compensated with a total of $\$ 100$ upon completion of the study for the seven daily diaries and \$10 was subtracted for each uncompleted diary. Participants were asked to sign the informed consent on the first page of the background survey and mail it back to the lab with the diary. Upon completion, compensation and debriefing explanations were mailed to the participants.

\section{Daily Measures}

\section{Frequency of Communication Modes}

The frequency of daily social interactions via each communication mode was included in a nightly diary entry which measured the amount of time participants spent interacting with their family and friends in-person, by telephone calling (using a telephone), text messaging (using a cellphone), and over the internet (such as email, Facebook, Twitter, Instant Messenger, etc.) not including video chat (such as Skype, Google Hangout). Participants responded using a fivepoint Likert scale with the following options, 1- "Not at all," 2- "One or two times today," 3- "A few times today," 4- "Several times today," and 5- "Nearly all day." Daily scores for each of the communication modes ranged from 1 to 5 . A higher score indicated a greater frequency of using a specific communication mode while a low score indicated more infrequent use of a specific communication mode. The internal consistency reliability of the daily rating for each communication mode was calculated across the seven study days. Cronbach's alpha for each communication mode was as follows: in-person: .835 , telephone: .860 , text messaging: .948 , internet: .889 .

\section{Daily Stress}

In order to determine the types of stressors, the Daily Inventory of Stressful Events (DISE) was developed, which proposed how sociodemographic, psychosocial, and situational elements contribute to daily stress exposure and reactivity (Almeida et al., 2002). To reduce participant burden, the diary only asked five of the seven most relevant items of DISE from the MIDUS Daily Diary study (Almeida et al., 2002).

\section{Stress Exposure}

Exposure to stress was the sum of the stressful events that occurred within the last $24 \mathrm{hr}$. Participants were asked "In the last $24 \mathrm{hr}$, did you have an argument with anyone," "a stressful event at home," "an encounter with a friend or family member that's stressful," "something that you could have argued/disagreed about but let it go," and "an event at school, work, or a volunteer setting that's stressful." Participants would respond with "yes" or "no" to each question. For each question, participants were informed to only select "yes" if the question referred to an event "other than what they have already mentioned in the previous questions." A "yes" response would yield a score of 1, and a "no" response would yield a score of 0 . Exposure to stress was measured by summing the total number of exposures to stress for each study day (Stress Exposure). Daily stress exposure scores ranged from 0 to 5 . Higher scores indicated higher exposure to stress while lower scores indicated lower exposure to stress.

\section{Stress Reactivity}

Reactivity or stress level was determined by the severity of the response for each interpersonal stressor based on a Likert scale ranging from 1-"Not at all," 2-“A little," 3-"Somewhat," and 4"Very." Participants were asked "how stressful was this for you?" for each of the stress exposure items they responded "yes" to. Only items participants had exposure to were counted for stress reactivity. The scale was recoded from 0 (not at all) to 3 (very). Stress reactivity was measured by the sum of severity for all stress items for each study day (Stress Reactivity). The possible daily stress reactivity score ranged from 0 to 15 . Higher scores indicated higher reactivity to stress while lower scores indicated lower reactivity to stress.

\section{Positive and Negative Affect Schedule}

Positive and Negative Affect Schedule (PANAS) consisted of a total of 22 items: nine items from the original PANAS scale (Watson 1988) and 12 items from the Positive and Negative Affect scale in Midlife Development Inventory (MIDI) (Mroczek \& Kolarz, 1998). Participants were asked to report how often during the day they felt positive and negative feelings based from a one (very slightly or not at all) to five (extremely) Likert scale. This questionnaire resulted in a score for both positive affect and negative affect (Mroczek \& Kolarz, 1998). Positive items include 11 items: "Cheerful," "In good spirits," "Extremely Happy," "Calm and peaceful," "Satisfied" (Mroczek \& Kolarz, 1998), "Full of life," "Enthusiastic," "Attentive," "Proud," "Active" (Watson 1988), and "In control of my life." The total daily positive affect score could range from 11 to 55, with a higher score indicating a higher level of positive affect. Negative items also contained 11 items: "So sad nothing could cheer you up," "Nervous," "Restless or fidgety," "Hopeless," "That everything was an effort," "worthless" (Mroczek \& Kolarz, 1998), "Afraid," "jittery," "Irritable," "Ashamed," and "Upset" (Watson 1988). Total daily negative affect scores could range from 11 to 55 , with a higher score indicating a higher level of negative affect.

\section{Covariates}

Covariates included participants' age, sex $(1=$ male, 2 = female), years of education (6-20 years), neuroticism, and social network size, because these variables have shown to be related to the outcome variables (Almeida \& Kessler, 1998; Grzywacz et al., 2004). 


\section{Neuroticism}

Neuroticism served as a covariate because past studies showed that those with higher neuroticism had more daily stress and negative affect (Mroczek \& Almeida, 2004). More neurotic individuals were also associated with more stress reactivity compared with less neurotic individuals (Bolger \& Zuckerman, 1995). Neuroticism was measured by calculating the mean across the following traits: moody, worrying, nervous, and calm (R). Participants indicated how well each of the adjectives described them on a Likert scale from 1 "A lot" to 4 "Not at all." All items for this trait except "calm" were reverse coded so higher scores reflected higher standing for neuroticism.

\section{Social Network Size}

Social network size served as a covariate because one's social network size is positively associated with frequency of contact with his or her social network members and well-being (Fiori et al., 2007; Van Tilburg, 1995). Participants were asked about the family and friends that make up their social circle. They were asked to write down the initials of those in their inner, middle, and peripheral circles (Kahn \& Antonucci, 1980). Each initial was counted with a score of 1 and was summed from the three categories of social network to determine the total number of people in the participant's social network, in this case, it would be the participants' social network size. The social network size score ranged from 1 to 72 .

\section{Procedure}

The present study represents a secondary analysis of an existing data set. Given the use of within-person analyses, the present study has a total of 1,015 diary entries (145 participants $\times 7$ days of diary entries). The observed power for the present study was computed with the available sample size (reported in the "Results" section). The study was approved by Brandeis University's Institutional Review Board. Before participating in the study, participants were prescreened for eligibility over the phone by completing the Pfeiffer questionnaire, a "short portable mental status questionnaire" consisting of 10 items to ensure that participants were mentally functioning and had no severe organic impairment. Participants were eligible if they had no more than two errors on the test (Pfeiffer, 1975). Once the eligibility was determined, the participant was sent a packet that contained informed consent, a background survey, seven daily dairies, a payment form, and an envelope for each daily diary to mail back to the lab (Robinson et al., 2016).

Participants were instructed to complete the background questionnaire the day before their first diary. The participants filled out the diary for seven days at consistent times every night before bed. Participants would specify the preferred time in the evening they would like to be called, and research assistants from the lab would call and remind the participants each evening to complete and send in their diary the next day. The response rate was high, with $92.4 \%$ of participants mailing back all seven diaries, $4.8 \%$ mailing back six of the seven diaries, and $1.4 \%$ mailing back four of seven diaries (Teshale \& Lachman, 2016). The diary included questionnaires that were of interest to the current study, as well as other questionnaires not included in the current study. Data and materials used for the current study can be obtained by contacting the authors.

\section{Data Analysis}

\section{Within-Person Analyses}

To examine whether the frequency of each communication mode (in-person, telephone calling, text messaging, and internet) varied in its relationship to stress exposure, stress reactivity, positive affect, and negative affect at a within-person level, a ("person-centered") daily change score of the frequency of each communication mode was calculated for each participant across the seven study days. Each participant in the study had seven days of ratings for the frequency of in-person communication (from day 1 to day 7). An average inperson score was computed as the mean of the participant's ratings for in-person communication from day 1 to day 7 . Then, for each participant's every study day (from day 1 to day 7), we subtracted the average in-person score from participant's daily rating of inperson communication to get his/her daily change score (personcentered In-Person) (Qian et al., 2014). The daily change score ("person-centered" In-Person) represents the fluctuation in frequency of in-person communication within-person over the study days. A positive person-centered in-person score represents a day with an above-average frequency of in-person communication for a participant, whereas a negative person-centered in-person score represents a below average frequency of in-person communication for the individual. The person-centered in-person score represents the withinperson aspect of frequency of in-person communication, as we can compare a person's day one to his/her day two. The average in-person score for each participant represents between-person frequency of inperson communication, indicating that the individual's average frequency of in-person communication is compared with that of another person. The same computations were used for frequency of telephone calling (Average Telephone Calling, Person-Centered Telephone Calling), frequency of text messaging (Average Text Messaging, Person-Centered Text Messaging) and frequency of internet communication (Average Internet, Person-Centered Internet).

The current study used multilevel modeling (MLM). The basic form of the multilevel model used for this study is as follows

$$
\begin{aligned}
& \text { 1. Level 1: Outcome } \mathrm{ij}_{\mathrm{ij}}=\beta_{0 \mathrm{j}}+\beta_{1 \mathrm{j}} \text { Predictor }_{\mathrm{ij}}+e_{\mathrm{ij}} \\
& \text { 2. Level 2: } \beta_{0 \mathrm{j}}=\gamma_{00}+u_{0 \mathrm{j}}
\end{aligned}
$$

The outcome variables (Outcome ${ }_{i j}$ ) (stress exposure, stress reactivity, and positive affect, and negative affect) at Level 1 are expressed as a within-person intercept $\left(\beta_{0 \mathrm{j}}\right)$, within-person predictor $\left(\beta_{1 \mathrm{j}}\right.$ Predictor $\left._{\mathrm{ij}}\right)$, which includes the frequency of all communication modes (person-centered in-person, person-centered telephone calling, person-centered text messaging, and person-centered internet), and within-person error term $\left(e_{\mathrm{ij}}\right)$. For Level 2, the within-person intercept is expressed as a function of fixed intercept (covariates and average in-person, telephone calling, text messaging, and internet). The intraclass correlation (ICC) was first calculated which indicates the proportion of total variance in each communication mode and outcome variable (stress exposure, stress reactivity, and positive affect, and negative affect) that is due to Level 2 units or individual effects. Sufficient variation in the outcome variables is necessary for further MLM analyses. 
The multilevel model was fitted to include the frequency of each communication mode (in-person, telephone calling, text messaging, and internet) to test whether the frequency of each communication mode varied in its relationship to stress exposure, stress reactivity, positive affect, and negative affect at a within-person level. In other words, on days in which one has more frequent social interactions using a specific communication mode, is this related to more or less stress exposure, stress reactivity, positive affect, and negative affect? The covariates and the average of each communication mode were controlled for these analyses.

\section{Results}

\section{The Intraclass Correlation}

\section{ICC for Each Communication Mode}

Given that we assessed the frequency of communication modes on 7 days, in addition to internal consistency reliability, the ICC was also calculated for each communication mode. The ICC indicated the proportion of total variance for each communication mode (in-person, telephone, text messaging, and internet) that was due to within-person effects. Similar to Harari et al., (2019) study which measured each communication mode objectively, the current study also showed sufficient within-person variability for participants across the week. For daily in-person communication, $45.44 \%$ of variation was between-person and $54.56 \%$ of variation was within-person. For daily telephone calling, $46 \%$ of variation was between-person and 54\% of variation was within-person. For daily text messaging, $70.18 \%$ of variation was between-person and $29.82 \%$ of variation was within-person. For daily internet use, $50.32 \%$ of variation was between-person and $49.68 \%$ of variation was within-person. These results suggested the importance of examining each communication mode on a day-to-day basis at the within-person level.

\section{ICC in Outcome Variables}

The ICC showed that overall, $34.8 \%$ of variation in daily stress exposure was between-person, and $65.2 \%$ of variation was withinperson. In addition, $26.1 \%$ of variation in daily stress reactivity was between-person, and $73.9 \%$ of variation was within-person. Overall, $36.1 \%$ of variation in daily positive affect was within-person, and $63.9 \%$ of variation was between-person. Moreover, $70.4 \%$ of variation in daily negative affect was between-person, and $29.6 \%$ of variation was within-person. These results indicated that there were sufficient variations in the outcome variables for further analyses.

\section{Descriptive and Between-Person Results}

The means, standard deviations, and correlations for all variables at the between-person level are included in Table 1. Age

Table 1

Means, Standard Deviations, and Intercorrelations Among Variables at the Between-Person Level $(\mathrm{N}=145)$

\begin{tabular}{|c|c|c|c|c|c|c|c|c|c|c|c|c|c|c|}
\hline & $\begin{array}{c}\text { Mor } \\
\%\end{array}$ & SD & 1 & 2 & 3 & 4 & 5 & 6 & 7 & 8 & 9 & 10 & 11 & 12 \\
\hline 1. Age (years) & 50.53 & 19.17 & - & & & & & & & & & & & \\
\hline 2. Sex ( $\%$ female $)$ & 60 & - & .09 & - & & & & & & & & & & \\
\hline $\begin{array}{l}\text { 3. Social network } \\
\text { size }\end{array}$ & 19.97 & 13.56 & $-.30^{* *}$ & .05 & - & & & & & & & & & \\
\hline 4. Neuroticism & 2.25 & .64 & -.08 & $.27^{* *}$ & -.09 & - & & & & & & & & \\
\hline 5. Education (years) & 15.11 & 2.45 & .12 & -.11 & .12 & $-.31^{* *}$ & - & & & & & & & \\
\hline 6. Daily in-person ${ }^{+}$ & 3.24 & .93 & -.10 & .06 & $.26^{* *}$ & -.16 & $.18^{*}$ & - & & & & & & \\
\hline $\begin{array}{l}\text { 7. Daily telephone } \\
\text { calling }^{+}\end{array}$ & 2.33 & .69 & .03 & .09 & .07 & -.03 & $-.23^{* *}$ & $.23^{* *}$ & - & & & & & \\
\hline $\begin{array}{l}\text { 8. Daily text } \\
\text { messaging }\end{array}$ & 2.12 & .99 & $-.68^{* *}$ & .05 & $.38^{* *}$ & -.01 & -.01 & $.28^{* *}$ & $.22^{* *}$ & - & & & & \\
\hline 9. Daily internet ${ }^{+}$ & 1.82 & .77 & $-.30^{* *}$ & -.09 & $.30^{* *}$ & -.08 & $.21^{* *}$ & $.26^{* *}$ & .05 & $.39 * *$ & - & & & \\
\hline $\begin{array}{l}\text { 10. Daily stress } \\
\text { exposure }^{\wedge}\end{array}$ & .99 & .75 & -.08 & -.07 & .05 & .08 & .07 & .03 & -.07 & .09 & .11 & - & & \\
\hline $\begin{array}{l}\text { 11. Daily stress } \\
\text { reactivity }\end{array}$ & 2.37 & 1.53 & -.03 & .08 & .01 & $.32^{* *}$ & $-.19^{*}$ & -.08 & .03 & .06 & -.06 & $.57^{* *}$ & - & \\
\hline $\begin{array}{l}\text { 12. Daily positive } \\
\text { affect }\end{array}$ & 32.60 & 8.64 & .08 & -.13 & $.17^{*}$ & $-.45^{* *}$ & $.24^{* *}$ & $.29^{* *}$ & .06 & .05 & .10 & -.12 & $-.28^{* *}$ & - \\
\hline $\begin{array}{l}\text { 13. Daily negative } \\
\text { affect }\end{array}$ & 15.00 & 5.48 & -.04 & .05 & $-.21^{*}$ & $.57^{* *}$ & $-.27^{* *}$ & $-.25^{* *}$ & -.04 & -.05 & -.16 & $.23^{* *}$ & $.53^{* *}$ & $-.59^{* *}$ \\
\hline
\end{tabular}

Note. Pearson's correlation was used for all continuous variables.

Point-Biserial correlation was used for all correlations involving sex. The normality for all the dependent variables within each sex was checked and only positive affect was normally distributed in each sex. Thus, all dependent variables except positive affect were log transformed and point biserial correlations were conducted again. There were no significant differences when comparing the original correlations with the correlations using log-transformed dependent variables. Therefore, the original correlations are presented.

$M=$ mean, $\mathrm{SD}=$ standard deviation.

${ }^{+}$Higher values on 1 to 5 scale for 5 items daily indicate greater frequency of that communication mode.

$\wedge$ Higher values indicate greater presence of the trait on a daily basis. Stress exposure ranged from 0 to 5 . Positive and negative affect each ranged from 11 to 55

${ }^{*}$ Higher values indicate higher self-reported stress reactivity on a daily basis, possible scores ranged from 0 to 15 .

* Correlation is significant at .05 Level (2-tailed).

*** Correlation is significant at .01 Level (2-tailed). 
had a strong negative correlation with the frequency of text messaging, $r=-0.68, p<.001$, and a moderate negative correlation with the frequency of internet communication, $r=-0.30$, $p<.001$. Sex was not related to the frequency of any communication mode or to the outcome variables. Similar to past work, social network size was positively skewed (Zahodne et al., 2019). A higher social network size was moderately related to more frequent in-person communication, $r=0.26, p=.002$, text messaging, $r=0.38, p<.001$, internet communication, $r=0.30$, $p<.001$, and positive affect, $r=0.17, p=.04$, as well as less negative affect, $r=-0.21, p=.01$. Higher neuroticism was moderately related to less positive affect, $r=-0.45, p<.001$, and more stress reactivity, $r=0.32, p<.001$, and strongly related to more negative affect, $r=0.57, p<.001$. Higher education was moderately related to more frequent in-person communication, $r=0.18, p=.03$, internet communication, $r=0.21, p=.01$, positive affect, $r=0.24, p=.004$, less telephone calling, $r=-0.23, p=.006$, stress reactivity, $r=-0.19$, $p=.03$, and negative affect, $r=-0.27, p=.001$ (see Table 1).

\section{Between-Person Results}

The between-person results for the association between each communication mode (Average In-Person, Average Telephone Calling, Average Text Messaging, and Average Internet) and stress and affect in the multilevel level model are presented in Table 2. Average In-Person, Average Telephone Calling, Average Text Messaging, and Average Internet did not predict stress exposure, stress reactivity, and negative affect. However, higher in-person communication predicted more positive affect at a between-person level, $\beta=1.73, p=.03$. Average Telephone Calling, Average Text Messaging, and Average Internet did not predict positive affect.

\section{Hypotheses Testing}

\section{Communication Modes and Stress Exposure and Reactivity}

The result was as predicted such that days with more text messaging were associated with more stressful events (1C), $\beta=0.15, p=.01$, while controlling for all other communication modes (power $=0.81$ ). However, person-centered text messaging was not significant for stress reactivity $(2 \mathrm{C}), \beta=0.27, p=.09$. Contrary to the predictions, the coefficients for person-centered in-person, telephone calling, and internet were not significant for stress exposure $(1 \mathrm{~A}, 1 \mathrm{~B}, 1 \mathrm{D})$, $\beta=0.009, p=.81, \beta=0.03, p=.52, \beta=0.03, p=.55$, or reactivity $(2 \mathrm{~A}, 2 \mathrm{~B}, 2 \mathrm{D}), \beta=0.004, p=.97, \beta=0.02, p=.88$, $\beta=-0.03, p=.79$, respectively (Figure 1 , Table 2 ).

\section{Communication Modes and Positive and Negative Affect}

Support was found for the prediction that days with more inperson communication were associated with more positive affect (3 A), $\beta=0.85, p<.001$, while controlling for other communication modes (power $=0.95$ ). However, no relationship between the frequency of in-person communication and negative affect was found ( $4 \mathrm{~A}$ ), $\beta=0.04, p=.73$. The prediction that more telephone communication than an individual's weekly average would be associated with less negative affect (4B), $\beta=-0.35, p=.05$, was supported (power $=0.82$ ). Contrary to predictions, the relationship between telephone calling and positive affect was not significant $(3 \mathrm{~B}), \beta=0.01, p=.97$. When the frequency of text messaging and internet was tested in relation to less positive and more negative affect, the prediction was only supported for more negative affect on high text messaging days $(4 \mathrm{C}), \beta=0.46, p=.03$ (power $=0.82$ ), but not for the internet $(4 \mathrm{D}), \beta=0.11, p=.51$. Results were not

Table 2

Within-Person Frequency of Communication Modes on Stress Exposure, Stress Reactivity, Positive Affect, Negative Affect

\begin{tabular}{|c|c|c|c|c|c|c|c|c|}
\hline \multirow[b]{2}{*}{ Predictors } & \multicolumn{2}{|c|}{ Stress exposure } & \multicolumn{2}{|c|}{ Stress reactivity } & \multicolumn{2}{|c|}{ Positive affect } & \multicolumn{2}{|c|}{ Negative affect } \\
\hline & $\begin{array}{l}\text { Unstandardized } \\
\text { coefficient }\end{array}$ & $S E$ & $\begin{array}{l}\text { Unstandardized } \\
\text { coefficient }\end{array}$ & $S E$ & $\begin{array}{l}\text { Unstandardized } \\
\text { coefficient }\end{array}$ & $S E$ & $\begin{array}{l}\text { Unstandardized } \\
\text { coefficient }\end{array}$ & $S E$ \\
\hline Intercept & -.28 & .72 & .92 & 1.45 & $31.40^{* * *}$ & 7.14 & $10.97^{*}$ & 4.33 \\
\hline Person-centered in-person & .009 & .04 & .004 & .11 & $.85^{* * *}$ & .25 & .04 & .13 \\
\hline Average In-Person & .002 & .08 & -.07 & .16 & $1.73^{*}$ & .79 & -.85 & .48 \\
\hline $\begin{array}{l}\text { Person-centered telephone } \\
\text { calling }\end{array}$ & .03 & .05 & .02 & .15 & .01 & .35 & $-.35^{*}$ & .18 \\
\hline Average telephone calling & -.05 & .11 & .05 & .23 & -.01 & 1.09 & .08 & .66 \\
\hline $\begin{array}{l}\text { Person-centered text } \\
\text { messaging }\end{array}$ & $.15^{*}$ & .06 & $.27^{\prime}$ & .16 & .15 & .41 & $.46^{*}$ & .21 \\
\hline Average text messaging & .09 & .10 & .07 & .20 & .53 & 1.02 & .33 & .62 \\
\hline Person-centered internet & .03 & .05 & -.03 & .13 & -.16 & .34 & .11 & .17 \\
\hline Average internet & .11 & .10 & -.10 & .21 & .30 & 1.00 & -.54 & .60 \\
\hline Age & .002 & .01 & .005 & .01 & .07 & .05 & -.003 & .03 \\
\hline $\operatorname{Sex}(1=$ male, $2=$ Female $)$ & -.17 & .15 & -.27 & .30 & -.77 & 1.47 & -1.22 & .89 \\
\hline Education (years) & .04 & .03 & -.03 & .06 & .11 & .31 & -.17 & .19 \\
\hline Neuroticism & $.20^{\prime}$ & .11 & $.87^{* * *}$ & .23 & $-5.29^{* * *}$ & 1.13 & $5.16^{* * *}$ & .69 \\
\hline Social network size & -.001 & .01 & .01 & .01 & .06 & .06 & -.05 & .03 \\
\hline \multicolumn{9}{|l|}{ Model fit } \\
\hline $\begin{array}{l}\text { Bayesian information } \\
\text { criterion (BIC) }\end{array}$ & \multicolumn{2}{|c|}{2518.36} & \multicolumn{2}{|c|}{2166.08} & \multicolumn{2}{|c|}{5662.23} & \multicolumn{2}{|c|}{4596.87} \\
\hline
\end{tabular}

${ }^{\prime} p<.1 . \quad * p<.05 . \quad * * p<.01 . \quad * * * p<.001$. 
significant for positive affect in relation to text messaging (3C) and internet (3D) days, $\beta=0.15, p=.71, \beta=-0.16, p=.63$, respectively (Figure 1, Table 2).

\section{Exploratory Results}

\section{Lagged Relationships}

In order to examine the directionality of the relationships, we tested the lagged relationship between each communication mode and the outcome variables (stress and affect). First, we examined whether the frequency of each communication mode on the previous day was related to stress and affect on the subsequent day. Results indicated a significant lagged relationship between frequency of text messaging and stress exposure, $\beta=0.13$, $p=.03$, which suggested that a higher previous-day frequency of text messaging was related to higher stress exposure on the subsequent day (power $=0.76)($ Table 3$)$. Previous-day stress and affect were examined in relation to the frequency of each communication mode on the subsequent day. Person-centered stress and affect were calculated the same way as person-centered scores for each communication mode. Results revealed that higher previous-day stress exposure was related to significantly less telephone calling on the subsequent day, $\beta=-0.06, p=.04$ (power $=0.93$ ) (Table 4). The lagged relationships between other communication modes were not significantly related to stress reactivity and affect.

\section{Discussion}

The present study examined the relationship between the frequency of communication modes (in-person, telephone calling, text messaging, and internet) and individual's psychological wellbeing (stress exposure, stress reactivity, positive affect, and negative affect) on a daily basis. Rather than only taking one snapshot of participants' lives, the daily diary design allowed us to probe the temporal association between participants' daily social interactions via different communication modes and their daily wellbeing. Given that social interactions and well-being can vary from day to day (Antonucci et al., 2014; Almeida, 2005), it is important to determine the daily aspects of social interactions that would be associated with one's daily health and well-being on the same or subsequent day.

\section{Communication Modes and Stress}

Results for MLM analyses supported our predictions that higher text messaging days were associated with more stress exposure, but it was not associated with stress reactivity. This could be due to the asynchronous nature of text messaging: while people may be exposed to more interpersonal stressful events, they can choose to ignore the message and not react or respond immediately. Rather, they can always return to the message at a much later time or whenever they feel more comfortable (Maier et al., 2012). Contrary to the predictions, in-person, telephone calling, and internet communication were not associated with same-day stress exposure and reactivity. This could be due to the synchronous nature of these communication modes, where conflicts or stressful events can be discussed instantaneously rather than with a delay (Wardecker et al., 2016).

\section{Lagged Relationships Between Communication Modes and Stress}

To examine directionality, the exploratory results using lagged analyses revealed that higher previous-day text messaging was related to higher stress exposure on the subsequent day. Furthermore, higher previous-day stress exposure was related to less telephone calling on the subsequent day. These findings are consistent with past studies and the CFO theory, which suggest that the lack of nonverbal, verbal, physical, and social cues in text-based CMC can more easily induce misinterpretation in one's message, whereas communicating with voice can better allow one to accurately express oneself and assess the receiver's reaction (Derks et al., 2008; Holtzman et al., 2017; Tsujita \& Rekimoto, 2011). Text-based CMC can provide a way of communicating with others in an efficient and timely manner, but it is important to note that using text-based CMC frequently for social interactions with family and friends is associated with greater stress exposure on both the concurrent and subsequent day. Thus, text messaging is related to stress for adults of all ages, not only for adolescents and young adults, as previous studies have found.

\section{Communication Modes and Affect}

In contrast to past studies that often used between-person analyses, the present study examined daily usages of different communication modes in relation to daily measures of positive and negative affect. As predicted and consistent with the CFO theory, more frequent in-person communication days were associated with more positive affect. The present study also added to the mixed findings on communication modes and negative affect. Higher text messaging days were associated with more negative affect. On the other hand, more telephone calling was associated with less same-day negative affect, suggesting that it is a good substitute when in-person communication is not possible. Even though CMC provides a simple way to communicate, it is in-person and telephone calling modes of communication that are associated with positive wellbeing. This study highlighted the benefits of in-person and telephone calling with the people within one's social network and the negative affect associated with the use of CMC for communication.

Contrary to the predictions, internet communication was not associated with same-day positive and negative affect. This could be because the aggregated term "internet" (not including video chat) used in the current study encompassed many different platforms (e.g., Facebook, instant messaging, and email). However, each platform differs in the feedback system. For example, email is asynchronous in nature because one may not know the real-time

\footnotetext{
${ }^{1}$ To examine the effects of the covariates, analyses (hypotheses testing and exploratory-lagged relationship) were conducted without the covariates All effects remained the same except for person-centered text messaging predicting same-day negative affect $(\beta=-0.36, p=.07)$. The covariates were added back to the model one at a time. When either age or social network size, or both age and social network size were added to the model, person-centered text messaging significantly predicted same day negative affect. Age and social network size are still important to control given their significant bivariate correlational relationships with both text messaging and negative affect (Table 1). By controlling for age and social network size, one can better understand the true effect of person-centered text messaging on same-day negative affect and reduce the risk of the omitted variable bias (Bafumi \& Gelman, 2006).
} 
Table 3

Lagged Relationship: Previous-Day Frequency of Communication Modes Predicting Subsequent-Day Stress and Affect

\begin{tabular}{|c|c|c|c|c|c|c|c|c|}
\hline \multirow[b]{2}{*}{ Predictors } & \multicolumn{2}{|c|}{ Stress exposure } & \multicolumn{2}{|c|}{ Stress reactivity } & \multicolumn{2}{|l|}{ Positive affect } & \multicolumn{2}{|c|}{ Negative affect } \\
\hline & $\begin{array}{l}\text { Unstandardized } \\
\text { coefficient }\end{array}$ & $S E$ & $\begin{array}{l}\text { Unstandardized } \\
\text { coefficient }\end{array}$ & $S E$ & $\begin{array}{l}\text { Unstandardized } \\
\text { coefficient }\end{array}$ & $S E$ & $\begin{array}{l}\text { Unstandardized } \\
\text { coefficient }\end{array}$ & $S E$ \\
\hline Intercept & -.23 & .34 & -.43 & 1.29 & .66 & 2.43 & -1.69 & 1.25 \\
\hline $\begin{array}{l}\text { Lagged person-centered } \\
\text { in-person }\end{array}$ & -.01 & .04 & -.07 & .14 & .19 & .25 & -.001 & .13 \\
\hline Average in-person & -.02 & .04 & -.06 & .14 & -.19 & .26 & .10 & .14 \\
\hline $\begin{array}{l}\text { Lagged person-centered } \\
\text { telephone calling }\end{array}$ & -.04 & .05 & -.33 & .18 & -.11 & .34 & -.06 & .18 \\
\hline Average telephone calling & .03 & .05 & .01 & .19 & -.45 & .34 & .03 & .19 \\
\hline $\begin{array}{l}\text { Lagged person-centered text } \\
\text { messaging }\end{array}$ & $.13^{*}$ & .06 & -.04 & .19 & -.31 & .38 & $.36^{\prime}$ & .20 \\
\hline Average text messaging & .06 & .05 & .01 & .16 & -.12 & .32 & .06 & .17 \\
\hline Lagged person-centered internet & .03 & .05 & .10 & .16 & .52 & .34 & -.01 & .18 \\
\hline Average internet & -.03 & .05 & -.20 & .18 & .12 & .33 & .04 & .17 \\
\hline Age & .004 & .002 & .001 & .008 & .003 & .02 & .01 & .01 \\
\hline Sex $(1=$ male, $2=$ Female $)$ & .004 & .07 & -.002 & .24 & -.09 & .47 & .12 & .25 \\
\hline Education (years) & -.002 & .01 & .04 & .06 & -.04 & .10 & .02 & .05 \\
\hline Neuroticism & -.03 & .05 & -.17 & .20 & .16 & .38 & -.08 & .22 \\
\hline Social network size & -.001 & .003 & .01 & .01 & .003 & .02 & -.004 & .01 \\
\hline Average stress exposure & $1.03^{* * *}$ & .04 & & & & & & \\
\hline $\begin{array}{l}\text { Lagged person-centered stress } \\
\text { exposure }\end{array}$ & -.05 & .04 & & & & & & \\
\hline Average stress reactivity & & & $1.12^{* * *}$ & .08 & & & & \\
\hline $\begin{array}{l}\text { Lagged person-centered stress } \\
\text { reactivity }\end{array}$ & & & -.06 & .06 & & & & \\
\hline Average positive affect & & & & & $1.03^{* * *}$ & .03 & & \\
\hline $\begin{array}{l}\text { Lagged person-centered positive } \\
\text { affect }\end{array}$ & & & & & -.04 & .04 & & \\
\hline Average negative affect & & & & & & & $1.03^{* * *}$ & .02 \\
\hline $\begin{array}{l}\text { Lagged person-centered } \\
\text { negative affect }\end{array}$ & & & & & & & .07 & .04 \\
\hline Model Fit & \multirow{2}{*}{\multicolumn{2}{|c|}{1759.2}} & \multirow{2}{*}{\multicolumn{2}{|c|}{1119.8}} & \multirow{2}{*}{\multicolumn{2}{|c|}{4314.6}} & \multirow{2}{*}{\multicolumn{2}{|c|}{3405.5}} \\
\hline $\begin{array}{l}\text { Bayesian information criterion } \\
\text { (BIC) }\end{array}$ & & & & & & & & \\
\hline
\end{tabular}

${ }^{\prime} p<.1 . \quad{ }^{*} p<.05 . \quad * * p<.01 . \quad * * * p<.001$.

"presence" of the receiver, and the time it takes for the receiver to get back to the sender is unknown. On the other hand, instant messaging can be synchronous because the sender can see whether others are online or typing, and the sender can expect an immediate real-time response from the other party, which can have an instant impact on one's mood (Sánchez et al., 2005). Future studies can consider separating each communication mode based on its synchronous and asynchronous nature, as that could impact positive and negative affect differently.

\section{Limitations and Future Directions}

This study had a relatively small sample size $(N=145)$ and participants were drawn from a convenience sample, mainly based in one metropolitan area, which could lead to questions of generalizability. We did not have information about how close the participants lived to their family and friends, and distance is likely to be related to frequency and type of communication. Even though lagged analyses were examined, the directionality or causality is still inconclusive. In addition, this study had limited diversity in terms of race and ethnicity, which could influence the frequency and impact of interactions as well as generalizability. Also, differences in culture should be taken into consideration when studying social interactions and health outcomes such as stress and affect.

There could be self-reported biases for the frequency of daily interactions. Nevertheless, a number of other studies also used a similar self-report approach to measure the frequency of different communication modes (e.g., social media, phone, and in-person) (Chan, 2015; Chen \& Li, 2017; Gerson et al., 2017; Kim \& Kim, 2017; Li \& Peng, 2019; Wardecker et al., 2016). The literature on time use and diary studies provides additional support for our method. Our study used a daily diary and assessed communication information at the end of each day, which can minimize memory biases because of the proximity in time of the recalled experience and frequency of usage (Bolger et al., 2003). Unlike longer-term self-reported surveys, that ask for a participant's time usage and experience retrospectively (e.g., over the past month or year), which can lead to greater inaccuracies in recall, the daily diary method shows a better match with an individual's actual experiences and time usage by minimizing the amount of time elapsed between experiences and the account of such experiences (Belli, 1998; Freedman et al., 2014; Kahneman et al., 2004). Both objective events and subjective feelings are less susceptible to recall biases if asked at the end of the day or even the next day in comparison with longer-term retrospective recall (Redelmeier \& Kahneman, 1996). 
Table 4

Lagged Relationship: Previous-Day Stress and Affect Predicting Subsequent-Day Frequency of Telephone Calling

\begin{tabular}{|c|c|c|c|c|c|c|c|c|}
\hline \multirow[b]{2}{*}{ Predictors } & \multicolumn{8}{|c|}{ Telephone calling } \\
\hline & $\begin{array}{l}\text { Unstandardized } \\
\text { coefficient }\end{array}$ & $S E$ & $\begin{array}{l}\text { Unstandardized } \\
\text { coefficient }\end{array}$ & $S E$ & $\begin{array}{l}\text { Unstandardized } \\
\text { coefficient }\end{array}$ & $S E$ & $\begin{array}{l}\text { Unstandardized } \\
\text { coefficient }\end{array}$ & $S E$ \\
\hline Intercept & $1.93^{* *}$ & .59 & $1.27^{*}$ & .63 & $1.95^{* *}$ & .64 & $1.89^{* *}$ & .61 \\
\hline $\begin{array}{l}\text { Lagged person-centered } \\
\text { in-person }\end{array}$ & -.02 & .03 & -.004 & .04 & -.02 & .03 & -.03 & .03 \\
\hline Average in-person & .10 & .07 & $.15^{*}$ & .07 & .10 & .07 & .10 & .07 \\
\hline $\begin{array}{l}\text { Lagged person-centered text } \\
\text { messaging }\end{array}$ & -.03 & .05 & .06 & .06 & -.04 & .05 & -.04 & .05 \\
\hline Average text messaging & $.27^{* *}$ & .08 & $.32 * * *$ & .09 & $.27^{* *}$ & .08 & $.27^{* *}$ & .08 \\
\hline Lagged person-centered internet & $-.08^{*}$ & .04 & -.08 & .05 & $-.09^{*}$ & .04 & $-.09^{*}$ & .04 \\
\hline Average internet & .02 & .09 & .03 & .09 & .01 & .09 & .02 & .09 \\
\hline Age & $.01^{* *}$ & .004 & $.01^{* *}$ & .004 & $.01^{* *}$ & .004 & $.01^{* *}$ & .004 \\
\hline $\operatorname{Sex}(1=$ male, $2=$ Female $)$ & .02 & .13 & .08 & .14 & .03 & .13 & .04 & .13 \\
\hline Education (years) & $-.07 * *$ & .03 & $-.07^{*}$ & .03 & $-.07 * *$ & .03 & $-.07 * *$ & .03 \\
\hline Neuroticism & -.06 & .10 & -.02 & .11 & -.07 & .11 & -.08 & .11 \\
\hline Social network size & -.0005 & .005 & -.004 & .005 & -.0003 & .005 & -.0003 & .005 \\
\hline Average stress exposure & -.04 & .08 & & & & & & \\
\hline $\begin{array}{l}\text { Lagged person-centered stress } \\
\text { exposure }\end{array}$ & $-.06^{*}$ & .03 & & & & & & \\
\hline Average stress reactivity & & & .01 & .04 & & & & \\
\hline $\begin{array}{l}\text { Lagged person-centered stress } \\
\text { reactivity }\end{array}$ & & & -.03 & .02 & & & & \\
\hline Average positive affect & & & & & -.001 & .008 & & \\
\hline $\begin{array}{l}\text { Lagged person-centered } \\
\text { positive affect }\end{array}$ & & & & & -.001 & .005 & & \\
\hline Average negative affect & & & & & & & -.001 & .01 \\
\hline $\begin{array}{l}\text { Lagged person-centered } \\
\text { negative affect }\end{array}$ & & & & & & & -.005 & .01 \\
\hline \multicolumn{9}{|l|}{ Model fit } \\
\hline $\begin{array}{l}\text { Bayesian information criterion } \\
\text { (BIC) }\end{array}$ & 1663.2 & & 987.4 & & 1676.1 & & 1665.6 & \\
\hline
\end{tabular}

Thus, the usage of the daily diary in our study is expected to provide a reasonably accurate representation of the daily frequency of different forms of communication. Nonetheless, future studies should consider using objective log data of social media usage to further examine the extent that the findings could be influenced by participants' subjective memories, as subjective reports have been found to overstate the relationship between screen time and mental health (Shaw et al., 2020).

Besides the frequency of social interactions via different communication modes, it would be interesting to consider in future studies whether the interactions were positive or negative, as the valence of the interaction could be related to stress and affect. For example, an interaction involving an argument would be more stressful than a more pleasant conversation. Moreover, it would be helpful to know the communication mode involved in each stressful event. Given the nature of the questions, the study could only examine cumulative daily stress, but not specifically who contributed to the participant's daily stress or whether the stressful event occurred before or after an instance of social interaction. In addition, because so few $(3.8 \%)$ of the participants in our sample used video chat, we did not include it in the present study. It would be of interest in the future to examine video chat usage, which includes social, physical, visual, and verbal cues, to see if it is more beneficial for reducing stress and negative affect than other modes that do not include both cues.
This study focused only on family and friends. It would be interesting to see whether interacting with other people (strangers, support groups, physicians/therapists/therapists, community members, and coworkers) rather than just family and friends influences stress and affect the same way. Furthermore, the data for this study were collected in the 2013-2014 period. Older adults were less likely to use text messages and the internet, although $80 \%$ of the older adults, 65 and older $(N=35)$, reported they used the internet regularly, and $88.6 \%$ used a cellphone. However, out of the older adults who used a cellphone, only $13 \%$ used text messages, and we do not know whether the cellphone they used was a smartphone. According to the (Pew Research Center, 2017b), ownership of smartphones for seniors ages 65 and older doubled from $18 \%$ to $42 \%$ since 2013. Thus, it will be important to collect new data to catch up with this growing trend. As young and middle-aged groups more consistently use CMC continue to develop into later adulthood, it is imperative to launch longitudinal studies for a more extended period to explore how the use of CMC in their daily lives could affect their stress and positive and negative affect longitudinally.

\section{Implications and Conclusion}

The study addresses whether social interactions with friends and family members via different communication modes are associated with well-being on a daily basis. With the increased availability of 
social applications and platforms that enable ease of connection with one's family and friends, the findings suggest that while these platforms can help maintain connections, in-person communication still plays an important role in one's positive affect. However, inperson communication is not always available or desired, whether due to distance or encouraged social distancing due to external factors like the COVID-19 pandemic. The current study suggests that on days with more telephone calling, individuals had less negative affect, which may be beneficial when in-person communication is not an option. Moreover, given the increase in technology and CMC usage in midlife and older adults, it is essential to understand how such daily communication style can contribute to their well-being and whether the different available communication modes can interfere or replace in-person communication for adults of all ages.

\section{References}

Almeida D. M. (2005). Resilience and vulnerability to daily stressors assessed via diary methods. Current Directions in Psychological Science, 14, 64-68. https://doi.org/10.1111/j.0963-7214.2005.00336.x

Almeida, D. M., \& Kessler, R. C. (1998). Everyday stressors and gender differences in daily distress. Journal of Personality and Social Psychology, 75(3), 670. https://doi.org/10.1037/0022-3514.75.3.670.

Almeida, D. M., Stawski, R. S., \& Cichy, K. E. (2011). Combining checklist and interview approaches for assessing daily stressors: The daily inventory of stressful events. In The handbook of stress science: Biology, psychology, and health (pp. 583-595). Springer Publishing Company.

Almeida, D. M., Wethington, E., \& Kessler, R. C. (2002). The daily inventory of stressful events: An interview-based approach for measuring daily stressors. Assessment, 9(1), 41-55.

Antonucci, T. C., Ajrouch, K. J., \& Birditt, K. S. (2014). The convoy model: Explaining social relations from a multidisciplinary perspective. The Gerontologist, 54(1), 82-92. https://doi.org/10.1093/geront/gnt118.

Antonucci, T. C., Ajrouch, K. J., \& Manalel, J. A. (2017). Social relations and technology: Continuity, context, and change. Innovation in Aging, 1(3), Article igx029. https://doi.org/10.1093/geroni/igx029.

Bafumi, J., \& Gelman, A. (2006). Fitting multilevel models when predictors and group effects correlate. Paper presented at the Annual Meeting of the Midwest Political Science Association. Chicago, IL. 20-23 April. Retrieved August 11, 2020 from http://www.stat.columbia.edu/ gelman/ research/unpublished/Bafumi_Gelman_Midwest06.pdf

Barley, S. R., Meyerson, D. E., \& Grodal, S. (2011). E-mail as a source and symbol of stress. Organization Science, 22(4), 887-906. https://doi.org/10 $.1287 /$ orsc.1100.0573.

Belli, R. F. (1998). The structure of autobiographical memory and the event history calendar: Potential improvements in the quality of retrospective reports in surveys. Memory, 6(4), 383-406. https://doi.org/10.1080/ 741942610 .

Bolger, N., Davis, A., \& Rafaeli, E. (2003). Diary methods: Capturing life as it is lived. Annual Review of Psychology, 54(1), 579-616. https://doi.org/ 10.1146/annurev.psych.54.101601.145030.

Bolger, N., \& Zuckerman, A. (1995). A framework for studying personality in the stress process. Journal of Personality and Social Psychology, 69(5), 890. https://doi.org/10.1037/0022-3514.69.5.890.

Chan, M. (2015). Mobile phones and the good life: Examining the relationships among mobile use, social capital and subjective well-being. New Media \& Society, 17(1), 96-113. https://doi.org/10.1177/ 1461444813516836.

Chen, H. T., \& Li, X. (2017). The contribution of mobile social media to social capital and psychological well-being: Examining the role of communicative use, friending and self-disclosure. Computers in Human Behavior, 75, 958-965. https://doi.org/10.1016/j.chb.2017.06.011.
Cornwell, B. (2011). Age trends in daily social contact patterns. Research on Aging, 33(5), 598-631. https://doi.org/10.1177/0164027511409442.

Derks, D., Fischer, A. H., \& Bos, A. E. (2008). The role of emotion in computer-mediated communication: A review. Computers in Human Behavior, 24(3), 766-785. https://doi.org/10.1016/j.chb.2007.04.004.

Dwyer, R. J., Kushlev, K., \& Dunn, E. W. (2018). Smartphone use undermines enjoyment of face-to-face social interactions. Journal of Experimental Social Psychology, 78, 233-239. https://doi.org/10.1016/j.jesp 2017.10.007

Fiori, K. L., Smith, J., \& Antonucci, T. C. (2007). Social network types among older adults: A multidimensional approach. The Journals of Gerontology. Series B, Psychological Sciences and Social Sciences, 62(6), P322-P330. https://doi.org/10.1093/geronb/62.6.P322.

Freedman, V. A., Conrad, F. G., Cornman, J. C., Schwarz, N., \& Stafford, F. P. (2014). Does time fly when you are having fun? A day reconstruction method analysis. Journal of Happiness Studies, 15(3), 639-655. https:// doi.org/10.1007/s10902-013-9440-0.

Gerson, J., Plagnol, A. C., \& Corr, P. J. (2017). Passive and active Facebook use measure (PAUM): Validation and relationship to the reinforcement sensitivity theory. Personality and Individual Differences, 117, 81-90. https://doi.org/10.1016/j.paid.2017.05.034.

Grzywacz, J. G., Almeida, D. M., Neupert, S. D., \& Ettner, S. L. (2004). Socioeconomic status and health: A micro-level analysis to exposure and vulnerability to daily stressors. Journal of Health and Social Behavior, 45(1), 1-16. https://doi.org/10.1177/002214650404500101.

Harari, G. M., Müller, S. R., Stachl, C., Wang, R., Wang, W., Bühner, M., Rentfrow, P. J., Campbell, A. T., \& Gosling, S. D. (2019). Sensing sociability: Individual differences in young adults' conversation, calling, texting, and app use behaviors in daily life. Journal of Personality and Social Psychology, 119(1), 204-228. https://doi.org/10.1037/ pspp0000245

Hess, U., \& Fischer, A. (2013). Emotional mimicry as social regulation. Personality and Social Psychology Review, 17(2), 142-157. https:// doi.org/10.1177/1088868312472607.

Holtzman, S., DeClerck, D., Turcotte, K., Lisi, D., \& Woodworth, M. (2017). Emotional support during times of stress: Can text messaging compete with in-person interactions? Computers in Human Behavior, 71, 130-139. https://doi.org/10.1016/j.chb.2017.01.043.

Jakubiak, B. K., \& Feeney, B. C. (2016). Keep in touch: The effects of imagined touch support on stress and exploration. Journal of Experimental Social Psychology, 65, 59-67. https://doi.org/10.1016/j.jesp.2016.04.001.

Kafetsios, K., Chatzakou, D., Tsigilis, N., \& Vakali, A. (2017). Experience of emotion in face to face and computer-mediated social interactions: An event sampling study. Computers in Human Behavior, 76, 287-293. https://doi.org/10.1016/j.chb.2017.07.033

Kahn, R. L., \& Antonucci, T. C. (1980). Convoys over the life course: Attachment, roles, and social support. In P. B. Baltes, O. Brim, (Eds.), Life-span development and behavior (Vol. 3, pp. 254-283). Academic Press

Kahneman, D., Krueger, A. B., Schkade, D. A., Schwarz, N., \& Stone, A. A. (2004). A survey method for characterizing daily life experience: The day reconstruction method. Science, 306(5702), 1776-1780. https://doi.org/10 $.1126 /$ science.1103572.

Kim, B., \& Kim, Y. (2017). College students' social media use and communication network heterogeneity: Implications for social capital and subjective well-being. Computers in Human Behavior, 73, 620628. https://doi.org/10.1016/j.chb.2017.03.033.

Kruger, J., Epley, N., Parker, J., \& Ng, Z. W. (2005). Egocentrism over e-mail: Can we communicate as well as we think? Journal of Personality and Social Psychology, 89(6), 925. https://doi.org/10.1037/0022-3514.89.6.925.

LaRose, R., Connolly, R., Lee, H., Li, K., \& Hales, K. D. (2014). Connection overload? A cross cultural study of the consequences of social media connection. Information Systems Management, 31(1), 59-73. https:// doi.org/10.1080/10580530.2014.854097 
Laumer, S., Maier, C., \& Weinert, C. (2013, June). The negative side of ICTenabled communication: The case of social interaction overload in online social networks. In Proceeding of ECIS [Conference section].

Li, L., \& Peng, W. (2019). Transitioning through social media: International students' SNS use, perceived social support, and acculturative stress. Computers in Human Behavior, 98, 69-79. https://doi.org/10.1016/j.chb .2019.03.011.

Maier, C., Laumer, S., Eckhardt, A., \& Weitzel, T. (2012). Online social networks as a source and symbol of stress: An empirical analysis. Digital and Social Networks.

McIntyre, C. W., Watson, D., Clark, L. A., \& Cross, S. A. (1991). The effect of induced social interaction on positive and negative affect. Bulletin of the Psychonomic Society, 29(1), 67-70. https://doi.org/10.3758/BF03334773.

Mroczek, D. K., \& Almeida, D. M. (2004). The effect of daily stress, personality, and age on daily negative affect. Journal of Personality, 72(2), 355-378. https://doi.org/10.1111/j.0022-3506.2004.00265.x.

Mroczek, D. K., \& Kolarz, C. M. (1998). The effect of age on positive and negative affect: A developmental perspective on happiness. Journal of Personality and Social Psychology, 75(5), 1333. https://doi.org/10.1037/ 0022-3514.75.5.1333.

Pew Research Center. (2010). Texting: Adults vs. Teens. Retrieved December 18, 2018 from Pew Internet website: www.pewinternet.org/fact-tank/ 2010/09/13/texting-adults-vs-teens/

Pew Research Center. (2017a). Internet/Broadband Fact Sheet. Retrieved December 18, 2018 from Pew Internet website: www.pewinternet.org/ fact-sheet/internet-broadband/

Pew Research Center. (2017b). Mobile Fact Sheet. Retrieved December 18, 2018 from Pew Internet website: www.pewinternet.org/fact-sheet/Mobile/

Pew Research Center. (2017c). Social Media Fact Sheet. Retrieved December 18, 2018 from Pew Internet website: www.pewinternet.org/fact-sheet/ social-media/

Pew Research Center. (2017d). Tech Adoptation Climbs Among Older Adults. Retrieved December 18, 2018 from Pew Internet website: http://www.pewinternet.org/2017/05/17/technology-use-among-seniors/

Pfeiffer, E. (1975). A short portable mental status questionnaire for the assessment of organic brain deficit in elderly patients. Journal of the American Geriatrics Society, 23(10), 433-441. https://doi.org/10.1111/j .1532-5415.1975.tb00927.x.

Przybylski, A. K., \& Weinstein, N. (2013). Can you connect with me now? How the presence of mobile communication technology influences faceto-face conversation quality. Journal of Social and Personal Relationships, 30(3), 237-246. https://doi.org/10.1177/0265407512453827.

Qian, X. L., Yarnal, C. M., \& Almeida, D. M. (2014). Is leisure time availability associated with more or less severe daily stressors? An examination using eight-day diary data. Leisure Sciences, 36(1), 3551. https://doi.org/10.1080/01490400.2014.860782.

Ravindran, T., Kuan, Y., Chua, A., \& Hoe Lian, D. G. (2014). Antecedents and effects of social network fatigue. Journal of the Association for Information Science and Technology, 65(11), 2306-2320. https:// doi.org/10.1002/asi.23122.

Redelmeier, D. A., \& Kahneman, D. (1996). Patients' memories of painful medical treatments: Real-time and retrospective evaluations of two minimally invasive procedures. Pain, 66(1), 3-8. https://doi.org/10.1016/ 0304-3959(96)02994-6.

Reinecke, L., Aufenanger, S., Beutel, M. E., Dreier, M., Quiring, O., Stark, B., Wölfling, K., \& Müller, K. W. (2017). Digital stress over the life span: The effects of communication load and internet multitasking on perceived stress and psychological health impairments in a German probability sample. Media Psychology, 20(1), 90-115. https://doi.org/10.1080/ 15213269.2015.1121832.

Rickenbach, E. H., Agrigoroaei, S., Hughes, M., \& Lachman, M. E. (2019). Control beliefs and susceptibility to the promises of memory improvement. Applied Cognitive Psychology, 2019, 1-11. https://doi.org/10.1002/acp.3544
Robinson, S. A., \& Lachman, M. E. (2018). Daily control beliefs and cognition: The mediating role of physical activity. Journal of Gerontology: Psychological Sciences, Series B. Advance online publication. https://doi.org/10.1093/geronb/gby081

Robinson, S. A., Rickenbach, E. H., \& Lachman, M. E. (2016). Selfregulatory strategies in daily life: Selection, optimization and, compensation and everyday memory problems. International Journal of Behavioral Development, 40, 126-136. Online publication July 1, 2015. https:// doi.org/10.1177/0165025415592187

Sacco, D. F., \& Ismail, M. M. (2014). Social belongingness satisfaction as a function of interaction medium: Face-to-face interactions facilitate greater social belonging and interaction enjoyment compared to instant messaging. Computers in Human Behavior, 36, 359-364. https://doi.org/10.1016/ j.chb.2014.04.004

Sánchez, J. A., Kirschning, I., Palacio, J. C., \& Ostróvskaya, Y. (2005, October). Towards mood-oriented interfaces for synchronous interaction. In Proceedings of the 2005 LatinAmerican conference on Human-computer interaction (pp. 1-7).

Shaw, H., Ellis, D., Geyer, K., Davidson, B., Ziegler, F., \& Smith, A. (2020). Quantifying smartphone "use": Choice of measurement impacts relationships between "usage" and health. Technology, Mind, and Behavior, 1(2).

Sproull, L., Kiesler, S., \& Kiesler, S. B. (1991). Connections: New ways of working in the networked organization. MIT Press.

Teshale, S., \& Lachman, M. E. (2016). Managing daily happiness: The relationship between selection, optimization and compensation (SOC) strategies and well-being in adulthood. Psychology and Aging, 31, 687692. Online publication Mar 24, 2015. https://doi.org/10.1037/ pag0000132

Thomée, S., Härenstam, A., \& Hagberg, M. (2011). Mobile phone use and stress, sleep disturbances, and symptoms of depression among young adults-a prospective cohort study. BMC Public Health, 11(1), Article 66. https://doi.org/10.1186/1471-2458-11-66.

Tsujita, H., \& Rekimoto, J. (2011, September). Smiling makes us happier: Enhancing positive mood and communication with smile-encouraging digital appliances. In Proceedings of the 13th international conference on Ubiquitous computing [Conference section] (pp. 1-10).

Van Tilburg, T. G. (1995). Delineation of the social network and differences in network size. In Living arrangements and social networks of older adults (pp. 83-96). VU University Press

Vanden Abeele, M., Schouten, A. P., \& Antheunis, M. L. (2017). Personal, editable, and always accessible: An affordance approach to the relationship between adolescents' mobile messaging behavior and their friendship quality. Journal of Social and Personal Relationships, 34(6), 875-893. https://doi.org/10.1177/0265407516660636

Wardecker, B. M., Chopik, W. J., Boyer, M. P., \& Edelstein, R. S. (2016). Individual differences in attachment are associated with usage and perceived intimacy of different communication media. Computers in Human Behavior, 59, 18-27. https://doi.org/10.1016/j.chb.2016.01.029.

Watson, D. (1988). Intraindividual and interindividual analyses of positive and negative affect: Their relation to health complaints, perceived stress, and daily activities. Journal of Personality and Social Psychology, 54(6), 1020. https://doi.org/10.1037/0022-3514.54.6.1020.

Watson, D., Clark, L. A., McIntyre, C. W., \& Hamaker, S. (1992). Affect, personality, and social activity. Journal of Personality and Social Psychology, 63(6), 1011. https://doi.org/10.1037/0022-3514.63.6.1011.

Zahodne, L. B., Ajrouch, K. J., Sharifian, N., \& Antonucci, T. C. (2019). Social relations and age-related change in memory. Psychology and Aging, 34(6), 751. https://doi.org/10.1037/pag0000369.

Received January 31, 2020

Revision received October 30, 2020

Accepted November 03, 2020 